\title{
Cuidando das relações no ensino médico
}

\section{Caring relationships in medical education}

Luciana Fernandes de Medeiros Azevedo', Agábio Diogenes Pessoa Neto², Caroline Manoela de Oliveira², Luisa Silva de Sousa ${ }^{2}$, Maria Beatriz Nóbrega Eberlin², Yngra Bastos Mesquita Minora de Almeida²

\begin{abstract}
RESUMO:
O artigo é um relato de experiência de um trabalho que teve como objetivo proporcionar momentos de escuta e reflexão sobre si mesmo como primeiro passo para o cuidado de si e para o desenvolvimento de uma postura dialógica. A ideia foi desenvolver espaços de reflexão sobre a humanização e o cuidado consigo mesmo e com o outro. O trabalho foi desenvolvido através de 05 rodas de conversa com 05 estudantes de medicina interessados em participar do projeto. No decorrer dos encontros, temas como relação aluno-professor, estudos de anatomia, sobrecarga de conteúdos e provas foram elencados como mobilizadores de angústia entre os estudantes. Faz-se necessário incluir esses temas no cotidiano de aulas e aprimorar a relação aluno-professor para efetivamente incutir o processo de humanização no ensino médico.
\end{abstract}

Palavras-chave: Estudantes de Medicina; Relação Estudante-Professor; Rodas De Conversa; Cuidado.

\begin{abstract}
This article is an experience report of a study that aimed to provide moments of listening and reflection as a first step to self-care and the development of a dialogical approach between medical students. The idea was to develop spaces for reflection on humanization and careful with yourself and with others. The work was developed through 05 rounds of conversation with 05 medical students interested in participating in the project. During the meeting, issues such as teacher-student relationship, anatomy studies, overload of content and exams were listed as mobilizers of distress among students. It is necessary to include these topics in daily classes and improve the student-teacher relationship to effectively instill the humanization process in medical education.
\end{abstract}

Key-words: Students, Medical; Student-Teacher Relationship; Rounds of Conversation, Care.

1. Doutora em Psicologia. Docente, Faculdade de Ciências da Saúde do Trairi (FACISA), Universidade Federal do Rio Grande do Norte (UFRN),

2. Estudantes de graduação do Curso de Medicina da Universidade Federal do Rio Grande do Norte
Correspondencia: Luciana Fernandes de Medeiros Azevedo Facisa/UFRN Av. Rio Branco, S/N - Santa Cruz/RN

Artigo recebido em 26/08/2013 Aprovado para publicação em 29/09/2014 


\section{Introdução}

O presente artigo é um relato de experiência de um trabalho desenvolvido ao longo do semestre 2013.1, com estudantes do curso de medicina de uma instituição de ensino superior federal. O trabalho foi desenvolvido através de rodas de conversa, mediadas pela primeira autora, tendo como participantes os demais autores.

O fortalecimento da medicina dentro dos moldes do modelo biomédico, proposto em meados do século $\mathrm{XX}$, trouxe muitos avanços para o diagnóstico e o tratamento de inúmeras doenças. Contudo, o que se constata na atualidade é uma crítica contundente a esse modelo, sobretudo por que priorizou a doença e não o doente. A tendência em classificar os sintomas em doenças e a ênfase na tecnologia médica, para exames e tratamentos, contribuiu também para que o médico aprendesse a lidar bem com a doença, mas não com a pessoa portadora dessa doença.

Um paciente que não apresenta uma doença fácil de ser diagnosticada pode ser um desafio para a medicina tradicional. Um exemplo são os casos da denominada doença dos nervos ou nervoso em que as pessoas apresentam múltiplos sintomas físicos $\mathrm{e}$ psíquicos e, que, normalmente, não completam os critérios diagnósticos de uma patologia específica. Em pesquisa recente, observou-se que boa parte dos prontuários analisados continha diferentes diagnósticos em um mesmo paciente. ${ }^{1}$ Esses diagnósticos eram dados, principalmente, em função dos sintomas físicos apresentados. Isso significa que cada vez que o paciente ia ao serviço com sintomas diferentes, recebia um diagnóstico distinto. Em síntese, o paciente possuía vários diagnósticos, mas não se compreendia o seu real problema. ${ }^{1}$ Isso mostra que muitos profissionais se baseiam mais nos sintomas apresentados no momento da consulta do que na história de vida e do sofrimento do paciente. loca ${ }^{2}$ :

Outro problema está de acordo com o que co-

A discordância entre médico e paciente na visão da doença e do processo de adoecer e nos objetivos a atingir com o tratamento repercute negativamente nos resultados obtidos (p.91).

Isso pode ser exemplificado, de um lado, pelo paciente que não aceita mais qualquer tipo de tratamento por pesquisar no Google e questionar as deci- sões médicas com o médico; de outro lado, o profissional que aprendeu a ser autossuficiente e que não quer ter seus procedimentos questionados ou reciclar seus conhecimentos.

Ainda nessa linha de raciocínio, os autores ${ }^{2}$ apontam que:

A transição epidemiológica com a mudança de predomínio de doenças agudas para doenças crônico-degenerativas tornará obrigatória a reincorporação da arte da medicina, com a substituição de objetivos de cura e de evitar a morte para o objetivo de cuidado das pessoas, considerando a perspectiva dessas pessoas. (p.92)

Mais adiante, os autores supracitados consideram que:

O modelo centrado em aspectos apenas biomédicos tenderia a inibir o crescimento moral do estudante de Medicina, comprometendo sua capacidade de sentir empatia e compaixão, e a boa prática clínica não existe separada de comportamentos éticos e profissionais, que dependem de maturidade moral $(2, p .93)$.

Nos últimos anos, os cursos de medicina passaram por modificações no currículo básico no intuito de fortalecer a medicina centrada no paciente e no cuidado, em detrimento da medicina centrada na doença e no diagnóstico nosológico. Isso significa que o médico precisa de uma formação que inclua discussões e vivências sobre humanidades no ensino médico através das artes, literatura e poesia com o objetivo de vivenciar e perceber as singularidades do ser humano e a focalizar a atenção sobre a pessoa, e não sobre o doente. ${ }^{3}$ Assim como a autora ${ }^{3}$, outros autores ${ }^{2,4}$ também compartilham a ideia de que é preciso proporcionar um espaço para aprimorar a sensibilidade dos estudantes em relação aos aspectos das relações humanas, a ver a medicina como arte e ciência do ser humano. A autora ${ }^{4}$ considera inclusive a necessidade de fortalecer o ensino transversal das humanidades no curso de medicina.

Fica evidente também que a humanização da medicina precisa começar com o resgate de valores como dedicação, empatia e solidariedade que deve partir do próprio profissional médico. Não adianta só falar desses temas, mas vivenciá-los. O estudo de ${ }^{5}$ elaborou uma proposta denominada de "conversas médicas" justamente com o intuito de possibilitar es- 
sas vivências. Esse trabalho incluiu principalmente a discussão dos aspectos psicológicos na formação do médico, a relação médico-paciente e concluiu com a afirmação da importância da interdisciplinaridade entre medicina e psicologia.

Assim, a formação médica deve partir dos seguintes princípios²:

1- exploração e interpretação, pelo médico, da doença e da experiência de adoecer do paciente, tendo a experiência de adoecer quatro dimensões: o sentimento de estar doente; a ideia a respeito do que está errado; o impacto do problema na vida diária; e as expectativas sobre o que deveria ser feito;

2- entendimento global da pessoa;

3- a busca de objetivos comuns, entre o médico e o paciente, a respeito do problema ou dos problemas e sua condução;

4- a incorporação de medidas de prevenção e promoção de saúde;

5- a melhora ou intensificação da relação médico-paciente;

6- a sua viabilidade em termos de custos e tempo. (p.91)

Considera-se que são muitas as demandas para os profissionais de saúde ${ }^{5,6}$ : a necessidade de reorganizar o saber-fazer na saúde, a rapidez da vida moderna, o advento das novas tecnologias, o questionamento dos valores antes hegemônicos, como o modelo biomédico. E, principalmente, a necessidade de se pensar a saúde em seu conceito mais ampliado que inclui os determinantes sociais da saúde e os aspectos psicológicos e antropológicos no surgimento e no agravamento de certas doenças. ${ }^{7}$

Diante desses princípios e ideias, fica evidente que o médico precisa se centrar no seu consulente, no sentido de que, muitas vezes, vai ser preciso ter paciência, compreensão e a arte de ouvir, além de buscar estabelecer uma relação baseada no diálogo. Porém, como fica o médico nesse percurso? E o estudante de medicina, será que consegue lidar com tantas demandas, desde o início do curso, tais como os estudos exaustivos de fisiologia, anatomia, histologia, entre outros, além dos temas ético-humanísticos? A que preço?

Uma das consequências de ser estudante de medicina é a suscetibilidade aos problemas psicológicos. $\mathrm{Na}$ pesquisa $\mathrm{de}^{8}$, fica evidente a presença da suspeita de transtornos mentais comuns (TMC) em $37,1 \%$ dos estudantes de medicina da instituição pesquisada. Os TMC's são caracterizados por diversos sintomas como esquecimento, dificuldade de concentração, insônia, irritabilidade, fadiga e queixas somáticas. ${ }^{8}$ São sintomas que não caracterizam um quadro psicopatológico grave, mas que trazem sofrimento psicológico significativo e, se não cuidados, podem vir a se agravar com o passar do tempo. Outro estudo, mais recente, ${ }^{9}$ também aponta um significativo índice, 33,6\%, de casos suspeitos de TMC entre estudantes de uma faculdade de medicina.

Alguns estudos, como os de ${ }^{10}$, apontam a importância da assistência psicológica aos estudantes de medicina. Nesse trabalho, os autores descrevem a implantação e os resultados obtidos com o desenvolvimento do Grupo de Assistência Psicológica ao Aluno (GRAPAL), na FMUSP, em 1986. Os autores identificaram a prevalência de transtornos de humor, sobretudo depressão, e transtornos de ansiedade entre os alunos, muitas vezes decorrentes da pressão dos estudos, pouco tempo para o lazer e contato com pessoas da família, bem como a constatação das dificuldades da profissão. A assistência psicológica oferecida foi essencial para acolher alguns desses alunos e prestar o cuidado necessário. Os autores citam que, entre 1986 e 2006, foram realizados 13.783 atendimentos. Esse número poderia ser ainda maior se não houvesse tantas faltas e desmarcações de consultas e/ ou se houvesse menos medo e preconceito de procurar ajuda psiquiátrica e/ou psicológica.

Acredita-se que existem outros trabalhos como esses desenvolvidos isoladamente nas universidades, mas ainda não fazem parte totalmente da cultura do ensino médico ou são trabalhos não publicados. Sabese que em muitas instituições há serviços de apoio psicológico aos estudantes e funcionários, mas trabalhos voltados exclusivamente aos estudantes de medicina ainda parecem poucos e isolados.

$\mathrm{O}$ aluno de medicina e o médico se deparam o tempo todo com limites: o limite dele como pessoa, o limite do paciente e o limite da própria medicina. ${ }^{11}$ Dessa maneira, lidar com o paciente de uma maneira mais profunda e compreensiva requer outras habilidades que nem sempre serão estudadas em livros ou apreendidas durante o curso. São aptidões pessoais, como a sensibilidade, a habilidade em lidar com situações difíceis, a paciência para o diálogo, a interpretação da linguagem do outro. Ou seja, é uma preparação pessoal, de enriquecimento das relações 
interpessoais e do desenvolvimento da criatividade, da sensibilidade e da intuição. Esses são aspectos essenciais para a clínica, mas que não é ensinado com aulas e textos.

Considerando as demandas aqui elencadas e a possível sobrecarga emocional e material que essas demandas podem gerar no estudante de medicina, considera-se que ele precisa ser escutado para aprender a escutar, que também precisa ser cuidado para cuidar. Ou seja, é preciso, primeiro, cuidar de si para poder cuidar do outro. Dessa maneira, o objetivo desse trabalho é analisar os encontros realizados com estudantes de medicina. Os encontros tinham como principal meta proporcionar momentos de escuta e reflexão sobre si mesmo como primeiro passo para o cuidado de si e para o desenvolvimento de uma postura dialógica.

O trabalho foi realizado através de rodas de conversa com 05 alunos do primeiro ano do curso de medicina de uma instituição federal. Houve cinco encontros no período de quatro meses, com aproximadamente $1 \mathrm{~h} 30 \mathrm{~min}$. de duração cada um. Os encontros foram mediados pela psicóloga, coordenadora do trabalho, que teve como papel central mediar a discussão, trazer material para o grupo e acolher os eventuais sentimentos despertados durante os encontros.

A psicóloga mediadora se fundamentou na perspectiva fenomenológico-existencial que enfatiza o encontro como um momento existencial e singular entre subjetividades ${ }^{12}$. As pessoas afetam e são afetadas pelo outro de maneira a acontecer o que se denomina de intersubjetividade e processo de interanimação dialógica. A metodologia das rodas de conversa é proposta por Paulo Freire com vistas ao empoderamento e desenvolvimento da autonomia de pessoas. ${ }^{13} \mathrm{O}$ trabalho foi fundamentado ainda no modelo dos grupos de encontro desenvolvidos por Carl Rogers que acolhe e cuida das diferentes subjetividades. ${ }^{14}$

As discussões realizadas nos encontros foram registradas por escrito, tanto pela coordenadora como pelos participantes. A análise do material construído ao longo dos encontros está fundamentada nos pressupostos fenomenológico-existenciais ${ }^{12}$ e na análise do discurso. ${ }^{15,16}$ Após leitura e discussão sobre cada encontro, os estudantes puderam tecer impressões acerca do que aconteceu com eles durante esse período e como o trabalho contribuiu para o andamento do semestre. Alguns trechos mais significativos dos relatos finais dos participantes foram selecionados para compor esse artigo por ora apresentado. Concomitan- tes aos trechos selecionados são apresentados comentários e análise dos mesmos a partir da literatura estudada. Com esse trabalho espera-se contribuir para a formação pessoal do aluno de medicina e fortalecer as bases humanísticas do ensino médico.

\section{Conversando sobre o cuidar, o cuidar de si e o cuidado com o outro}

Os estudantes participantes do trabalho estavam no segundo período do curso de medicina no período das rodas de conversa. Jovens cheios de expectativas, com uma média de 19 anos, contentes com a aprovação no vestibular difícil e concorrido, os participantes se disponibilizaram a se encontrar mensalmente para conversar sobre o cuidado e a formação do médico.

O convite para participar do trabalho foi feito para toda a turma do segundo período, cerca de 50 alunos. No entanto, apenas cinco desejaram participar dos encontros. Uma das explicações possíveis é a alta carga horária de estudos, provas e trabalhos o que realmente acaba por tomar muito tempo desses estudantes. Outra explicação diz respeito ao interesse e motivação para participar de um trabalho como esse. Nem todos se sentem disponíveis para usar seu tempo "conversando", "discutindo", fica muito evidente o valor dado aos estudos de anatomia, fisiologia e histologia que geralmente aparece como mais importante do que qualquer outra coisa. Outro estudo ${ }^{5}$ também aponta essa dificuldade de participação nesse tipo de trabalho.

No estudo $\mathrm{de}^{17}$, a necessidade de serviços de apoio psicopedagógico e psicossocial se fazem necessários nos cursos de medicina. Porém, os autores constatam a pouca efetividade dos serviços de apoio, sobretudo quando há pouca procura por parte dos alunos. De acordo $\mathrm{com}^{4}$, ainda há uma cultura na educação médica de que o estudo das humanidades não é tão importante, além de muitos professores arraigados ao modelo tradicional. Isso pode dificultar a motivação dos alunos em participar de oficinas, atividades e outras propostas que visem esse tipo de reflexão. Pois, é como se fosse "perda de tempo".

Pode ser também que esse formato de trabalho não seja atrativo para parte dos estudantes. Talvez seja necessário pensar outros formatos de ação ou, ainda, elaborar diferentes ações com o intuito de mudar essa cultura. ${ }^{4}$ Nos estudos ${ }^{8,9,10}$, ficou evidente a dificuldade dos serviços de acolhimento e cuidado mediante o alto número de faltas e desmarcações. Talvez seja 
necessário rever a metodologia do trabalho desenvolvido nesses serviços e/ou as práticas de cuidado desenvolvidas.

Tendo sido feitas essas considerações sobre o pouco número de participantes, os encontros serão analisados a seguir. $\mathrm{O}$ primeiro ponto discutido no grupo foi a ideia de cuidado, qual o sentido de se reunir uma vez por mês para conversar. Para uma das participantes, o trabalho proposto se resumiu no seguinte:

Cuidado é uma palavra muito utilizada por nós, estudantes de medicina, e quase sempre o enfoque são os outros, nossos pacientes. E quanto a nós? Será que não deveríamos também nos incluir nesse público alvo do cuidado? Realmente, todo e qualquer profissional desde sua vida estudantil deve receber uma atenção a mais, especialmente, nós da área da saúde. (Estudante 01)

O trecho acima mostra um despertar para o cuidado de si como profissional de saúde, tema bastante pertinente nos discursos oficiais nos últimos anos. Infelizmente, nem todo estudante ou profissional de saúde procura o cuidado nos primeiros anos de trabalho, seja psicoterapia, participação em grupos de encontro ou outro tipo de ação semelhante. Isso fica bem claro no estudo de ${ }^{17}$, quando constatam que boa parte dos participantes de sua pesquisa desconhece serviços de apoio psicológico e/ou não procura ajuda quando necessário. Nesse caso, os autores observaram significativa prevalência de transtornos psiquiátricos menores, tais como sintomas depressivos e ansiedade entre os estudantes de medicina e a automedicação, mas não a procura por serviços de apoio. Para esses autores, os serviços de apoio psicológico e psiquiátrico precisam ser mais bem divulgados, além de suprirem as reais necessidades da população.

Em geral, esses serviços demandam uma motivação interna, uma disponibilidade pessoal e afetiva para procurar e se engajar. Muitos consideram que são serviços inacessíveis do ponto de vista financeiro, mas nem sempre esse é o real motivo. Ou ainda, não os procuram para não sobrecarregar uma rotina já complicada de aulas e provas. Pressupõe-se que a ideia de procurar uma psicoterapia, grupo de encontro ou mesmo participar de qualquer atividade que se baseie na reflexão de si mesmo, denota uma fragilidade que não condiz com o estereótipo do médico: onipotente, onipresente, forte, não pode chorar, não pode sofrer. Com a inserção do eixo ético-humanístico e das humanidades no curso de medicina, espera-se desconstruir esses estereótipos que só contribuem para o distanciamento entre médicos e pacientes.

Ainda em relação ao tema do cuidado, outra participante coloca que:

Estudar medicina tem um peso histórico na sociedade brasileira. Você não é apenas um estudante, mas sim o estudante que foi capaz de entrar na Universidade Federal e no curso mais concorrido e, por isso, há a grande responsabilidade de dominar a matéria, não ser um mau aluno e ainda atuar na sociedade como modelo. (Estudante 02)

Nesse trecho fica evidente a cobrança de ser um bom aluno, sobretudo por ser um estudante de medicina. Esse dado também aparece no estudo de ${ }^{8}$ como uma das possíveis causas para o desenvolvimento de TMC. A estudante 02 continua com seu depoimento:

Essa admiração miscigenada com certa cobrança revela-se apenas a ponta de um iceberg de responsabilidades atribuídas aos futuros médicos. Aliado a tal ponta estão a exaustiva grade curricular e as dificuldades de integrar o técnico com a humanização nessa nova era da medicina.

Nesse trecho, a estudante 02 corrobora os estudos de (8), (9) e (10) que também mostraram a alta carga horária de aulas e a grande quantidade de matérias para estudar e assimilar em pouco tempo como um dos fatores que contribuem para o sofrimento psicológico dos alunos. Ela continua:

Todo o peso desse iceberg parece cair sobre o estudante desde o primeiro dia no curso e, caso não haja maior preocupação com a sua saúde física e mental, o bloco de gelo pode desmoronar sobre suas costas. A partir dessa constatação, tornase essencial maior atenção para o cuidar de si, afinal, estar bem consigo é o primeiro passo para cuidar do outro.

Existem algumas formas para conquistar esse cuidado pessoal e cada um deve encontrar a de maior identificação. Na minha conturbada rotina de estudante de medicina, uma oportunidade única surgiu: a criação de um grupo, acompanhado por uma professora e psicóloga, para desabafarmos nossas aflições e termos um tempo para cuidar da nossa saúde mental, em especial. 
O grupo tornou-se essencial para o meu crescimento como ser humano e profissional, pois abordávamos situações vividas no momento e podíamos, juntos, encontrar soluções ou simplesmente escutar o outro e ser ouvido. Foram reuniões em que praticamos nosso exercício democrático de expor opiniões e respeitá-las, utilizando cada uma de forma aditiva na construção de profissionais exemplares em um futuro próximo (Estudante 02).

$\mathrm{O}$ discurso da estudante 02 evidencia a necessidade de trabalhos como esse ao longo do curso de medicina. Não só conversar sobre a humanização no atendimento, mas também refletir sobre suas questões pessoais, dificuldades e conflitos que muito provavelmente irão repercutir nas relações sociais, sobretudo na relação médico-paciente. Isso tem sido feito com sucesso no trabalho $\mathrm{de}^{9}$ como mencionado anteriormente. Nessa linha de raciocínio, alguns autores comentam ${ }^{18}$ :

Nesse sentido, o ensino de Humanidades tem caráter transversal, ou seja, deve ocorrer ao longo da graduação em diversos momentos e lugares, e a formação humanística corresponde ao desenvolvimento de competências ético-relacionais que se dá de forma processual em vários cenários de ensino- aprendizagem do currículo formal informal e nas diversas interações das pessoas no ambiente acadêmico. (18, p. 309)

Essas competências ético-relacionais não se aprendem somente em disciplinas específicas, mas na convivência, no dia a dia, na mediação dessas relações e no cuidado consigo mesmo. Um dos temas mais tocados nos relatos dos participantes foi a importância de refletir melhor sobre a humanização e a formação do médico. Como coloca a estudante 03:

No primeiro encontro nós conversamos sobre como seria o projeto e quais as nossas expectativas. Logo na segunda reunião, começamos a discutir a relação professor-aluno e as dificuldades que enfrentamos no curso em relação a isso. Temos muitos professores, cada assunto é lecionado por um diferente, o que dificulta a criação de um vínculo. Não há como estabelecer uma relação de confiança e sentimos falta disso. Alguns professores também são muito acadêmicos e se limitam a expor o assunto. Ouvimos desde o nosso primeiro dia na faculdade que "a medicina precisa ser humanizada". Mas muitos docentes não nos ajudam com isso. Entrar em uma sala de aula e jogar o conteúdo sem nos ensinar como aplicar esse conhecimento não nos forma médicos melhores. Devemos praticar a medicina mais humana, mas como? Qual o limite entre o envolvimento com os pacientes e a humanização? (Estudante 03).

As questões que envolvem a relação professoraluno foram bastante discutidas na maior parte dos encontros. Isso mostra a importância e a necessidade do vínculo saudável entre professor e aluno. A consolidação do eixo ético-humanístico perpassa pela vinculação efetiva e afetiva entre professores e alunos. De fato, não adianta exigir que os alunos desenvolvam a escuta e o cuidado quando, algumas vezes, não se sentem escutados e/ou cuidado pelos professores. Essa questão se coloca muito subjetiva, afinal, o que significa ser um bom professor? Como o docente pode ser humanizado ou humanista sem perder a autoridade, a necessidade de bem avaliar os estudantes? O próprio Paulo Freire já afirmava a importância das emoções no processo ensino-aprendizagem. Nesse sentido, é preciso ter afeto, é necessário que os estudantes se sintam, de alguma forma, afetados pelo processo educativo.

Os autores ${ }^{18}$ apontam que:

Nas escolas médicas, a construção da postura ética e o pensamento crítico e reflexivo se desenvolvem a partir de disciplinas e condutas que se aprendem nas salas de aula, nos laboratórios e, principalmente, observando os professores em ação na prática cotidiana. Ao mesmo tempo em que afirmam que os alunos, pela observação dos mestres, "modelam" comportamentos e, assim, de certa forma, constroem uma identidade médica, tais estudos contrariam a suposição de que os alunos, por serem adultos com personalidades já formadas, não modificariam valores e atitudes mediante aprendizado na escola médica (18, p.309).

Isso mostra a importância de se considerar as diferentes relações que são construídas entre professores e alunos na aprendizagem e na construção de uma postura ética e humanística. Fica claro que a boa relação professor-aluno é essencial para a aprendizagem e para o desenvolvimento das competências ético-humanísticas. Esse deveria ser um ponto de maior discussão entre os docentes do curso de medicina e de qualquer outro curso da área de saúde. Em um estudo recente sobre a relação professor-estudante, muitos alunos se comportavam de forma diferente dependendo de quem era o professor ${ }^{18}$. Isso mostra a importância da atitude do professor durante a aula ou discussão do caso: 
Nos diversos cenários, observamos os alunos assistindo ao professor, calados, atentos ou distantes, poucas vezes interagindo, concordando, questionando ou discordando. A obediência e a submissão aos que estão acima caracterizariam a atitude do aluno em situação de aprendizado. A hierarquia médica era bem estratificada - como acontece nas corporações - , determinava comportamentos e criava distâncias para a interação entre professores e alunos (18 p. 310).

Nesse estudo, as autoras encontraram três possibilidades do ser $\operatorname{professor}^{18}: 1$ ) a relação pedagógica baseada na onipotência do professor em que este estimula a competitividade e intimida o aluno, não havendo diálogo, nem a prática ético-humanística; 2) a relação pedagógica baseada na construção do vínculo, em que o professor consegue criar vínculos tanto com pacientes como com os alunos; 3) a relação pedagógica baseada na desqualificação do aluno em que o professor, com sua atitude em sala de aula, consegue mostrar que é dono do saber e que o aluno não é nada.

A atuação de professores capazes de construir vínculos com alunos e pacientes em situações mais ativas de ensino - uma vez que os alunos são adultos em processo de investimento na autoidentidade, e não meros receptores de conteúdos transmitidos pelo professor - mediante o reconhecimento do outro em sua alteridade e a busca de entendimento recíproco promove verdadeiras experiências de intersubjetividade que criam condições para o desenvolvimento humanístico. São situações em que o aluno aprende o diálogo, a comunicação, a responsabilidade compartilhada e a consideração aos afetos envolvidos, seus e dos outros (18 p. 314).

Esse estudo responde, então, à indagação da estudante 03 e dos demais participantes que se sentiram, em alguns momentos, incomodados com a postura de alguns professores. Provavelmente, alguns professores também se sentiram aborrecidos com as faltas e atrasos dos alunos, mas fica evidente que cabe ao professor estabelecer uma relação mais dialógica e acolhedora para que eventuais problemas possam ser minimizados. Um dos participantes resume bem a necessidade de professores afetivos e efetivos:

Acrescenta-se a isso mais uma reflexão própria: os professores "educadores" que estimulam toda essa mania de acerto total acabam incentivando também a competitividade dentro da nossa turma e vale salientar que turmas de medicina, infelizmente, já tem muita competitividade normalmente, com pessoas que querem saber mais que as outras e às vezes fazem de tudo para conseguir isso. Felizmente, em minha turma, isso não é comum, porém, se existirem mais professores assim, poderá instigar esse comportamento (Estudante 04).

\section{As dificuldades enfrentadas e as possíveis soluções}

Outro tema bastante comum nos encontros do grupo foi a sobrecarga de atividades e o pouco tempo para estudar tantas matérias. Essa situação traz uma angústia muito grande aos estudantes que nem sempre conseguem administrar todas as exigências. Uma das participantes comentou:

Não podemos deixar o "mundo da medicina" nos engolir; precisamos encontrar tempo para outras atividades que nos dão qualidade de vida e melhoram nosso rendimento no próprio curso. Por isso, apesar de toda a rotina pesada, encontro tempo para fazer inglês que me deixa de bom humor por que posso ir pra aula pelo hobby de aprender uma nova língua; além disso, participo de uma organização internacional de estudantes de medicina, a IFMSA, que me dá espaço para entrar em contato com a população através de campanhas relacionadas à saúde, indo além das paredes da sala de aula. Participo, também, de um grupo de ação social que escolhe lugares carentes para levar doações e manhãs de alegria; há ainda os projetos de extensão da Universidade, o Contagiarte e o Mediarte, que nos dão espaço de entrar em contato com os pacientes, não para falar de suas enfermidades, mas para trocar, na verdade, momentos de descontração. Precisamos dessas atividades extras para não nos alienarmos na medicina que não é tudo, pois todo ser humano precisa de cultura e senso crítico para ser um bom cidadão. (Estudante 05)

Observa-se a necessidade de conciliar os estudos da graduação com outras atividades extracurriculares, sobretudo aquelas de caráter lúdico, de contato com outras pessoas, de enriquecimento cultural. Acredita-se que para uma formação ético-humanística se faz necessária a participação em ações de extensão e pesquisa multidisciplinares que "quebrem" um pouco com a hegemonia racionalista de que só tirar notas boas e decorar todo o tratado é suficiente. Os estu- 
dantes apontam a importância de várias experiências que possam contribuir para o desenvolvimento da sensibilidade e postura centrada na ética do cuidado. É como afirma um dos participantes:

Temos todos, o direito de se divertir, relaxar, até porque os médicos que não fazem isso conseguem chegar a um nível de estresse tão elevado que comprometem sua saúde e o seu atendimento. Chegam ao ponto de tratar mal um paciente por que não dormiu bem ou por que não se alimentou naquele dia. E o paciente tem culpa de sua falta de cuidado? Não. (Estudante 04).

Esse discurso deixa clara a importância do cuidado para o próprio profissional. O excesso de trabalho e a sobrecarga não fazem bem a ninguém, mas parece que os serviços de saúde pública são adoecedores por si só. Essa questão está relacionada com as condições de trabalho, outro ponto bastante polêmico, discutido em trabalho anterior ${ }^{7}$, mas que não será abordado nesse artigo em função dos atuais objetivos.

Outra situação de grande impacto e dificuldade para os estudantes são os contatos com as peças anatômicas. Essa situação foi bem resumida pela estudante 03:

Outro tema muito relevante e discutido durante nossas reuniões é o contato com os cadáveres no anatômico. Costumamos olhar para as partes isoladas e não como um todo. Eu, particularmente, vejo as mais diversas peças, mas procuro não pensar que ali havia uma pessoa com família e sonhos... Não sei se conseguiria estudar pensando em tudo isso... O maior choque é quando vemos o corpo inteiro, o rosto e identificamos a pessoa ali naquele momento. Ninguém nos pergunta o que achamos disso tudo quando temos nossa primeira aula de anatomia. Simplesmente nos apresentam a essa realidade e precisamos aprender a lidar com ela. (Estudante 03)

Esse depoimento aponta para uma necessidade de haver algum tipo de preparação para os estudos de anatomia com cadáveres. Seria bastante salutar abrir um espaço para conversar sobre os sentimentos em relação a estudar com o corpo de pessoas mortas. A morte ainda é um tabu na sociedade ocidental e o médico é justamente um dos profissionais que mais tem dificuldade em lidar com a morte. A impressão que fica é que os estudantes de medicina são lançados nos estudos de anatomia com corpos de pessoas mortas e eles que aprendam a lidar sozinhos com os sentimentos despertados. Embora esse aspecto não tenha sido elencado nos estudos supramencionados $8,9,10$, fica evidente que o mal estar em estudar anatomia pode contribuir para o sofrimento psicológico, sobretudo naqueles estudantes mais sensíveis.

Observa-se que, em geral, há espaço nos cursos de medicina para as matérias técnicas, mas não para conversar sobre esses temas mais relacionados ao sofrimento humano e aos sentimentos despertados nos estudantes. Sentimentos esses que podem se refletir em uma dificuldade futura e próxima de lidar com o sofrimento e a morte de um paciente. Tudo isso é um reflexo da sociedade cartesiana ocidental que normalmente menospreza os sentimentos.

Somado a isso temos também a relação médico-paciente. Começamos a visitar enfermarias no Hospital Universitário e nos deparamos com realidades diferentes durante o semestre. Mais uma vez não me senti preparada, havia sempre a dúvida de até aonde vai essa relação, quais os limites de envolvimento emocional, como perguntar sem invadir a privacidade do paciente... Como abordar a sexualidade, por exemplo? Como entrar em um quarto e perguntar a um paciente sobre sua vida sexual sem ser indelicado? Esse é um tabu em nossa sociedade e que causa constrangimento a quem pergunta e, principalmente, a quem responde. Novamente, sinto que nos dizem o que devemos fazer, mas não nos mostram como! (Estudante 03).

Diante desse discurso, reitera-se a necessidade de um espaço em que não sejam só discutidos os aspectos técnicos da profissão, mas também para vivenciar as relações humanas e conversar sobre as angústias e medos inerentes ao exercício da medicina. Espaço que pode sim ser incluído na rotina normal de aulas no momento em que o professor visualiza essa lacuna e a trabalha de forma coerente e concisa com seus alunos.

\section{Considerações finais}

O objetivo desse artigo foi descrever e analisar as experiências de estudantes de medicina em um grupo terapêutico sobre o cuidado e o cuidar. Os encontros foram muito interessantes por que os participantes se sentiram bastante à vontade para expressar suas angústias diante do curso. Ficou claro que esse tipo de trabalho pode ser bastante enriquecedor do ponto 
de vista psicológico, pois favorece um espaço de fala em que os sentimentos são valorizados e cuidados.

A maioria dos temas abordados pelos estudantes como possíveis precursores de sofrimento psicológico também aparecem na literatura como a sobrecarga de matérias e as inúmeras cobranças. Contudo, os estudos de anatomia e as relações professor-aluno e médico-paciente são também temas importantes de serem considerados nos cursos de medicina.

O eixo ético-humanístico pode ser ainda mais enriquecido com ações semelhantes por que complementam o que vem sendo discutido em sala de aula: a importância das relações pessoais e interpessoais, a necessidade de expressar os sentimentos e serem acolhidos e a prática vivencial desse tipo de relação. Algo que fica bastante evidente é a necessidade desse tipo de discussão perpassar transversalmente por todo o curso de medicina, não somente nos primeiros anos. A angústia gerada diante da morte, no ensino de anatomia, pode se agravar diante de um paciente em cuidados paliativos ou sem possibilidades de cura que o estudante provavelmente vai se defrontar no internato ou na residência médica. Se isso não é trabalhado em todos os anos de formação, pode ser que esse estudante acabe solapando seus sentimentos e desenvolvendo mecanismos de defesa mais prejudiciais como a arrogância, a frieza e outras formas mais negativas de expressar essas angústias.

Ficou evidente também a necessidade de se repensar a relação professor-aluno. $\mathrm{O}$ docente pode ser mais afetivo com os alunos, isso não irá prejudicar seu desempenho acadêmico, nem misturar os papéis. $\mathrm{O}$ professor pode continuar avaliando com rigor seu alunado, mas sem perder a disponibilidade, o interesse e a motivação em ver que seu aluno está aprendendo e não só decorando os diferentes termos técnicos. $\mathrm{O}$ aluno pode aprender de duas formas: com ou sem emoção. Quando ele aprende com emoção, com afeto e acolhimento, ele vai aprender não só o conteúdo técnico, mas a atitude e a postura diante da vida que vão se refletir no contato com seu paciente. Quando ele aprende sem emoção, pode acontecer de perder, ao longo do caminho (de)formativo, o olhar acolhedor, o calor e a disponibilidade emocional de estar com o outro. Esse processo pode ser mais doloroso por que quando a emoção não é expressa adequadamente, aparece sob outros aspectos: os vícios, as doenças, o mau humor crônico, a depressão e a irritabilidade.

\section{Referências:}

1. Azevedo, LFM, Alvarez, PES. Sofrimento psicológico na atenção básica: incidência e práticas de cuidado. FAPERN; 2012 (Relatório final do projeto de pesquisa).

2. Ribeiro MMF, Amaral CFS. Medicina centrada no paciente e ensino médico: a importância do cuidado com a pessoa e o poder médico. Rev Bras Educ Med. 2008; 32: 90-7.

3. Giordano S. Medical Humanities: An E-Module at the University of Manchester Cambridge. Camb. q. healthc. ethics.2010; 19, 446-57.

4. Rios IC. Humanidades e medicina: razão e sensibilidade na formação médica. Ciênc. saúde coletiva.2010; 5 (suplem.01), 1725-32.

5. Mello, DRB, Leite, CL, Campos, MGSC, Alvez Filho, RCA. Alçando Voo: a experiência de ampliar o diálogo entre psicologia e medicina. Rev. bras. educ. méd. 2012; 36: 234-42.

6. Rego S, Gomes AP, Siqueira-Batista R. Bioética e humanização como temas transversais na formação médica. Cad. ABEM 2007; 3: 24-33.

7. Azevedo LFM. Nervos: rede de discursos e práticas de cuidado na atenção básica no município de Natal/RN. Natal/ RN: 2010. Doutorado [Tese] - Universidade Federal do Rio Grande do Norte.

8. Fiorotti KP, Rosson RR, Borges LK, Miranda AE. Transtornos mentais comuns entre os estudantes de medicina: prevalência e fatores associados. J Bras Psiquiatr. 2010; 59: 1723.

9. Rocha ES, Sassi, AP. Transtornos mentais menores entre estudantes de medicina. Rev Bras Educ Méd.2013; 37: 21016.

10. Millan LR, Arruda, PCV. Assistência psicológica ao estudante de medicina: 21 anos de experiência. Rev Assoc Med Bras. 2008; 54: 90-4.

11. Ramos-Cerqueira ATA, Lima MCP, Torres AR, Reis JRT, Fonseca NMV. Era uma vez... contos de fadas e psicodrama auxiliando alunos na conclusão do curso médico. Interface Comun Saúde Educ. 2005; 9: 81-9.

12. Dutra, E. A narrativa como uma técnica de pesquisa fenomenológica. Estud. psicol.2002; 7, 371-8.

13. Azevedo, LFM. Práticas de cuidado em saúde mental: uma perspectiva da psicologia social e saúde comunitária. Curitiba: Ed. CRV, 2012.

14. Rogers CR. Grupos de encontro. Martins Fontes: São Paulo, 2009.

15. Spink, MJP, Menegon, VM. A pesquisa como prática discursiva: Superando os horrores metodológicos. In: Spink, MJP. Práticas discursivas e produção de sentidos no cotidiano: Aproximações teóricas e metodológicas. São Paulo: Cortez; 1999. p. 63-92.

16. Locke, T. Critical discourse analysis. London/UK: Continuum International Publishing Group, 2004.

17. Cunha, MAB, Neves, AAF, Moreira, ME, Hehn, FI, Lopes, TP Ribeiro, CCF, Watanabe, APF. Transtornos psiquiátricos menores e procura por cuidados em estudantes de medicina. Rev Bras Educ Méd. 2009, 33: 321-8.

18. Rios IC, Schraiber LB. A Relação Professor-Aluno em Medicina - um estudo sobre o encontro pedagógico. Rev Bras Educ Med. 2012. 36: 308-16. 